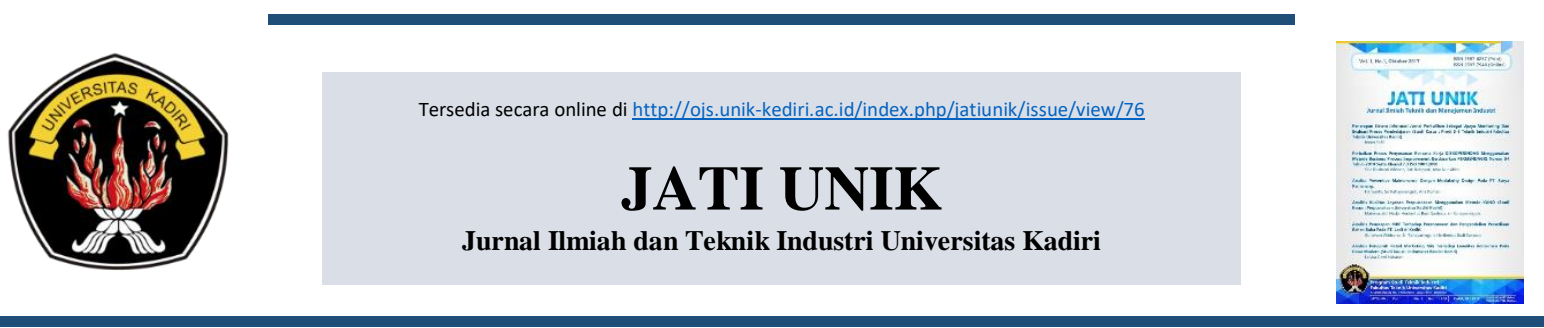

\title{
Pengembangan Kursi Kerja Ergonomis di UKM Tenun Ikat Medali Mas
}

\author{
Ary Permatadeny Nevita ${ }^{(1)}$ \\ (1) Program Studi Teknik Industri, Fakultas Teknik, Universitas Nusantara PGRI Kediri \\ Email : arypermata@ unpkediri.ac.id ${ }^{(1)}$
}

\section{Informasi Artike \\ Riwayat Artikel : \\ Received : 13 - September -2019 Revised : 26 - September -2019 \\ Accepted : 25 - Oktober - 2019}

Kata kunci :

Ergonomics Anthropometry

Work Station Design

Sitting Posture

Work Chair

\section{A bstract}

The role of humans as a source of labor in SME weaving is still very dominant in the production process, especially when the production process of converting yarn into fabric with non-machine looms. Sitting position during the process of weaving activities that lasts a long time with 8 hours per day, causes the sitting position to be less comfortable and cause complaints of pain in the back or spine. The purpose of this study is to produce an ergonomic work chair design with an anthropometric approach to improve comfort, reduce fatigue and other health effects caused by sitting positions that are less comfortable than the previous work chair, by focusing the work chair design on human body size. The results of this study are the development of weaving work chairs can be achieved by the addition of the backrest and cushion on the seat cushion of the chair as well as the addition of high-low chair settings according to anthropometry of workers compared to pre-existing weaving work chairs. Anthropometric measurements using the 5th and 95th percentiles obtained the dimensions of the work chair dimensions: 1) The height of the chair from the floor $95 \mathrm{~cm}, 2)$ The height of the seat cushion from the floor $52 \mathrm{~cm}$, 3) The width of the seat base $39 \mathrm{~cm}, 4$ ) The width of the backrest $35 \mathrm{~cm}, 5)$ Back length $31 \mathrm{~cm}$, 6) Back height $49 \mathrm{~cm}$.
Untuk melakukan sitasi pada penelitian ini dengan format : A. Kristanto and D. A. Saputra, "Perancangan Meja dan Kursi Kerja yang Ergonomis pada Stasiun Kerja Pemotongan Sebagai Upaya Peningkatan Produktivitas," J. Ilm. Tek. Ind., 2011.

\begin{abstract}
A b s trak
Peranan manusia sebagai sumber tenaga kerja pada UKM tenun ikat masih sangat dominan dalam proses produksinya terutama saat kegiatan proses produksi pengubah benang menjadi kain dengan alat tenun bukan mesin (ATBM). Posisi duduk pada saat proses pelaksaan kegiatan menenun yang berlangsung lama dengan waktu 8 jam per hari, menyebabkan posisi duduk menjadi kurang nyaman dan
\end{abstract}


mengakibatkan keluhan sakit terhadap punggung ataupun tulang belakang. Tujuan dari penelitian ini adalah menghasilkan rancangan kursi kerja yang ergonomi dengan pendekatan antropometri untuk meningkatkan kenyamanan, mengurangi kelelahan dan dampak kesehatan lain yang disebabkan akibat posisi duduk yang kurang nyaman dari kursi kerja sebelumnya, dengan memfokuskan rancangan kursi kerja pada ukuran tubuh manusia. Hasil penelitian ini adalah pengembangan kursi kerja tenun dapat dicapai dengan penambahan sandaran serta bantalan pada alas tempat duduk pada kursi serta penambahan pada pengaturan tinggi rendah kursi sesuai dengan anthropometri pekerja dibandingkan dengan kursi kerja tenun yang sudah ada sebelumnya. Pengukuran secara anthropometri menggunakan persentil ke-5 dan ke-95 maka diperoleh rancangan dimensi kursi kerja: 1) Tinggi kursi dari lantai 95 $\mathrm{cm}, 2$ ) Tinggi alas duduk dari lantai $52 \mathrm{~cm}, 3$ ) Lebar alas kursi $39 \mathrm{~cm}$, 4) Lebar sandaran $35 \mathrm{~cm}, 5$ ) Panjang sandaran $31 \mathrm{~cm}, 6)$ Tinggi sandaran $49 \mathrm{~cm}$.

\section{Pendahuluan}

Proses pengerjaan kerajian tenun ikat bisa diselesaikan secara manual maupun otomatis sehingga perlu diperhatikan tingkat kesehatan dan keselamatannya. UD Medali Mas berlokasi di kawasan/sentra industri kerajinan tenun yang bertempat di Bandar Kidul Kecamatan Mojoroto Kota Kediri. UKM ini pengolah benang menjadi kain tenun dengan produksi berbagai macam kain tenun seperti, kain sutra, kain semi sutra, kain katun, syal dan sarung serta berbagai macam motif yang dihasilkan. Serangkaian proses pengerjaan/pengoperasian mesin tenun mulai mengubah benang sampai menjadi tenunmasih dilakukan secara manual sehingga akan mempengaruhi kinerja dari para pekerjanya [1],[2]. Posisi dan tempat duduk pekerja awalnya pada kursi yang atasannya dikasih bantal atau pakaian bekas untuk menyangga pantat sehingga terkesan kurang ergonomis karena bantal atau kain itu diikat sendiri dengan tali dan itu pun mudah goyang tanpa adanya penyangga punggung sehingga saat pekerja istirahat tidak bisa merebahkan punggungnya secara nyaman [3]. Proses pengoperasian mesin tenun dengan kondisi tempat duduk yang kurang nyaman tersebut dapat mengakibatkan sakit ringan di bagian pinggang [4], [5]. Berdasarkan permasalahan di atas perlu dilakukan inovasi perancangan kursi kerja yang nyaman sehingga dapat mengurangi keluhan sakit pada bagian pinggang serta memfokuskan rancangan kursi kerja berdasarkan ukuran tubuh manusia [6], [7] Penelitian ini bertujuan untuk memperbaiki posisi duduk pekerja yang nyaman, dan merancang kursi kerja yang ergonomis dengan pendekatan anthropometri [4], [8], [9].

\section{Tinjauan Pustaka}

\subsection{Ergonomi}

Ergonomi berasal dari bahasa latin, yaitu ergon yang berarti "kerja" dan nomos yang berarti "hukum alam". Ergonomi didefinisikan sebagai suatu ilmu yang mempelajari 
interaksi antara manusia dengan lingkungan dan alat kerja yang dipakai sehingga dapat berperan dalam menyelesaikan masalah ketidak serasian antara manusia dengan peralatan yang digunakan saat bekerja [10]. Ergonomi merupakan pendekatan manusia dalam bekerja secara optimal dan efisien. Penerapan Ergonomi bertujuan untuk [11]: (a) Meningkatkan perbaikan fisik dan mental dengan mencegah cidera dan kesalahan akibat kerja, beban kerja fisik dan mental menjadi turun, (b) Meningkatkan kesejahteraan sosial dengan sistem pengorganisasian yang baik dan meningkatkan kerjasama di tempat kerja. (c) Menciptakan keseimbangan dalam berbagai aspek yaitu aspek teknis, ekonomis, antropologis, dan budaya dari setiap sistem kerja yang dilakukan sehingga akan tercipta kualitas kerja dan kualitas hidup. Kedua aspek ini berpengaruh pada tingkat produktifitas kerjanya. Pelaksanaan ergonomi dapat memberikan keuntungan yang dirasakan pada tingkat individu dan organisasi [12].

\subsection{Anthropometri}

Anthropometri adalah cabang ilmu ergonomi yang berhubungan dengan pengukuran dimensi tubuh manusia [13]. Anthropometri dapat diterapkan sebagai dasar ukuran perancangan suatu fasilitas yang disesuaikan dengan dimensi tubuh manusia berdasarkan alat yang akan dikembangkan sehingga menjadikan tenaga kerja dapat bekerja secara nyaman, baik dan efisien. Supaya rancang bangun suatu produk bisa sesuai dengan orang yang mengoperasikannya, maka pengukuran data anthropometri harus memenuhi beberapa prinsip [14]. Prinsip yang digunakan dalam penelitian ini adalah prinsip merancang produk dengan mengikuti klasifikasi terlalu besar maupun terlalu kecil dibandingkan rata-rata ukuran tubuh manusia secara mayoritas [15]. Ukuran dimensi maksimum yang digunakan adalah nilai persentil ke-90, ke-95, atau ke-99 sedangkan ukuran dimensi minimum digunakan persentil ke-1, ke-5, atau ke-10. Secara umum persentil yang digunakan persentil ke-95 dan ke-5 [16].

\subsection{Perancangan Desain Stasiun Kerja dengan Sikap Kerja Duduk}

Jenis pekerjaan dapat mempengaruhi posisi tubuh saat bekerja. Masing-masing posisi kerja mempunyai dampak yang berbeda. Bekerja dengan posisi duduk mempunyai beberapa keuntungan yaitu: pembebanan pada kaki, pemakaian energi dan keperluan untuk sirkulasi dapat dikurangi namun apabila sikap duduk terlalu lama dapat menyebabkan otot perut melembek dan tulang belakang akan melengkung sehingga cepat lelah [17], [18]. Mengingat posisi duduk mempunyai keuntungan dan kerugian, maka perlu dipertimbangkan jenis pekerjaan apa saja yang sesuai dilakukan dengan posisi duduk agar tidak menimbulkan efek negatif pada tubuh manusia [6].

\section{Metode Penelitian}

Didalam tahapan penelitian ini, digunakan metode penelitian untuk mempermudah alur penelitian. Metode penelitian yang dilakukan sebagai berikut :

1. Model Pengembangan

Mengembangkan kursi kerja yang sudah ada di UKM Tenun Ikat Medali Mas menjadi kursi kerja yang lebih nyaman sehingga para pekerja dapat dengan nyaman melakukan aktivitas kerjanya. Melalui beberapa prosedur dalam mengembangkan kursi kerja tenun 
yaitu dengan melakukan pengukuran terhadap karyawan agar diperoleh rata-rata ukuran tingkat kenyamanan kursi kerja yang telah dikembangkan [19]. Tahapan model pengembangan diawali untuk mengetahui sebagai berikut :

a. Ergonomi

Ergonomi merupakan pendekatan manusia dalam bekerja secara optimal dan efisien. Penerapan Ergonomi bertujuan untuk [11]: (a) Meningkatkan perbaikan fisik dan mental dengan mencegah cidera dan kesalahan akibat kerja, beban kerja fisik dan mental menjadi turun, (b) Meningkatkan kesejahteraan sosial dengan sistem pengorganisasian yang baik dan meningkatkan kerjasama di tempat kerja. (c) Menciptakan keseimbangan dalam berbagai aspek yaitu aspek teknis, ekonomis, antropologis, dan budaya dari setiap sistem kerja yang dilakukan sehingga akan tercipta kualitas kerja dan kualitas hidup. Kedua aspek ini berpengaruh pada tingkat produktifitas kerjanya.

b. Antropometri

Anthropometri dapat diterapkan sebagai dasar ukuran perancangan suatu fasilitas yang disesuaikan dengan dimensi tubuh manusia berdasarkan alat yang akan dikembangkan sehingga menjadikan tenaga kerja dapat bekerja secara nyaman, baik dan efisien.

c. Perancangan Desain Stasiun Kerja dengan Sikap Kerja Duduk

Mengingat posisi duduk mempunyai keuntungan dan kerugian, maka perlu dipertimbangkan jenis pekerjaan apa saja yang sesuai dilakukan dengan posisi duduk agar tidak menimbulkan efek negatif pada tubuh manusia [6].

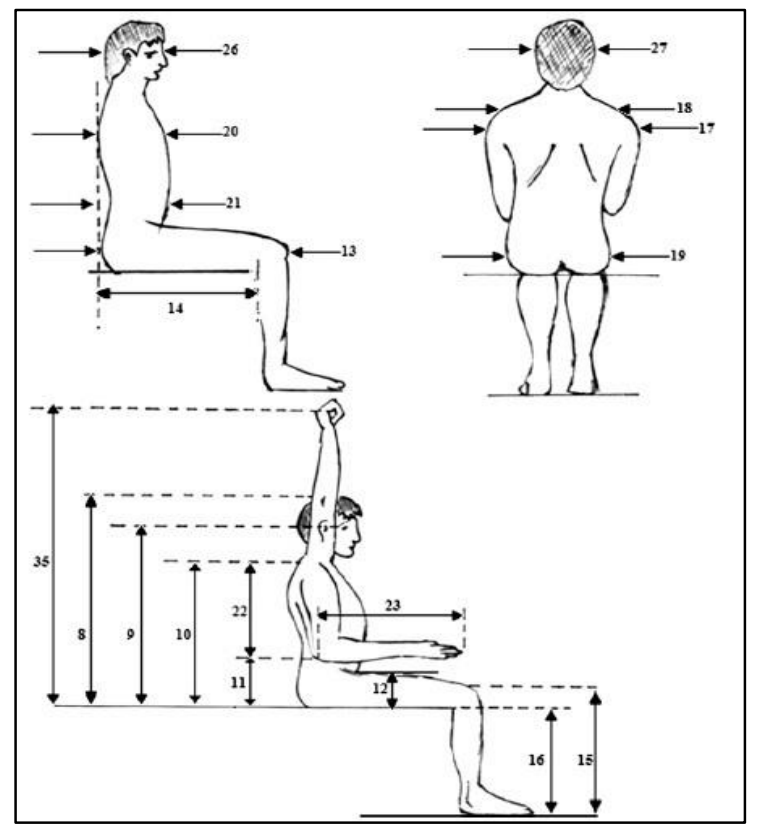

Gambar 1 Stasiun Kerja untuk Kerja dalam Posisi Duduk

Pekerjaan yang dilakukan dengan posisi duduk, tempat duduk yang dipakai harus memungkinkan untuk melakukan variasi perubahan posisi. Ukuran tempat duduk 
disesuaikan dengan dimensi ukuran anthropometri pemakainya [20], [21]. Fleksi lutut membentuk sudut 90 derajat. Dengan telapak kaki bertumpu pada lantai atau injakan kaki. Jika landasan kerja terlalu rendah, tulang belakang akan membungkuk kedepan, dan jika terlalu tinggi bahu akan terangkat dari posisi rileks, sehingga menyebabkan bahu dan leher menjadi tidak nyaman. Pedoman untuk mengatur ketinggian landasan kerja pada posisi duduk sebagai berikut [3] :

a. Menyediakan meja yang dapat diatur turun dan naik.

b. Landasan kerja harus memungkinkan lengan menggantung pada posisi rileks dari bahu, dengan lengan bawah mendekati posisi horizontal atau sedikit menurun (sloping down slightly).

c. Ketinggian landasan kerja tidak memerlukan fleksi tulang belakang yang berlebihan

2. Uji Coba Model/ Produk

Uji coba model/produk dengan pengembangan terhadap kursi kerja tenun yang sudah ada sebelumnya menjadi kursi kerja yang lebih efisien dan efektif serta lebih nyaman dalam melakukan aktivitas kerja yaitu dengan cara melakukan penilaian atau pengukuran terhadap posisi duduk pekerja di UKM Tenun Ikat Medali Mas yang kurang nyaman [9], [22]. Pertimbangan pengukuran secara anthropometri dengan perhitungan persentile, maka akan dapat diketahui perancangan kursi kerja tenun yang lebih nyaman

\section{Hasil dan Pembahasan}

\subsection{Studi Lapangan}

Pengukuran dilakukan langsung terhadap 8 orang pekerja dibagian tenun sekaligus melakukan proses wawancara untuk mengetahui keinginan pekerja terhadap pengembangan kursi kerja [23]-[25]. Pengukuran dilakukan untuk mencari data rata-rata anthropometri dengan persentil sehingga proses pengembangan atau perancangan kursi kerja bisa dilakukan [13], [17]. Hasil pengamatan dan pengukuran diperoleh sebagai berikut :

Tabel 1 Data Anthropometri Pekerja Tenun Ikat Medali Mas

\begin{tabular}{|l|l|}
\hline \multicolumn{2}{|c|}{ Hasil Pengamatan } \\
\hline \\
\hline
\end{tabular}

(Sumber : Olah data) 
Tabel 2 Data Antropometri Pekerja Tenun Ikat Medali Mas

\begin{tabular}{|c|c|c|c|c|c|c|c|c|}
\hline Dimensi/ Pekerja & 1 & 2 & 3 & 4 & 5 & 6 & 7 & 8 \\
\hline Tinggi Siku Duduk & 25,6 & 28,21 & 30 & 26,12 & 24,81 & 29,07 & 26,3 & 27,1 \\
\hline Lebar Bahu & 30,91 & 26,51 & 25,62 & 26,1 & 24 & 28,11 & 30,1 & 26,01 \\
\hline Tinggi Poplietal & 48,21 & 45,6 & 47,12 & 50,76 & 50,51 & 49,89 & 51,5 & 48,16 \\
\hline $\begin{array}{c}\text { Tinggi Bahu } \\
\text { Duduk }\end{array}$ & 47,01 & 42 & 43,03 & 50,11 & 43,05 & 44 & 39 & 39 \\
\hline Lebar Pinggul & 34,1 & 27,99 & 26,15 & 24,6 & 27,8 & 26,99 & 25,8 & 26,1 \\
\hline
\end{tabular}

(Sumber : Olah data)

Tabel 3 Data Rerata Klasifikasi Dimensi dan Kelas Berdasarkan Ukuran Percentile

\begin{tabular}{|c|c|c|}
\hline \multirow{2}{*}{} & \multicolumn{2}{|c|}{$\begin{array}{c}\text { Ukuran Percentile } \\
(\mathrm{cm})\end{array}$} \\
\cline { 2 - 3 } & 5 & 95 \\
\hline Tinggi Siku Duduk & 26,19 & 28,12 \\
\hline Lebar Bahu & 24,81 & 29,48 \\
\hline Tinggi Poplietal & 47,59 & 50,32 \\
\hline $\begin{array}{c}\text { Tinggi Bahu } \\
\text { Duduk }\end{array}$ & 40,99 & 45,60 \\
\hline Lebar Pinggul & 23,73 & 31,65 \\
\hline
\end{tabular}

(Sumber : Olah data)

Tabel 4 Rancangan Dimensi Kursi

\begin{tabular}{|c|c|c|}
\hline No. & Dimeni Kursi & $(\mathrm{cm})$ \\
\hline 1 & Tinggi kursi dan lantai & 96 \\
\hline 2 & Tinggi alas duduk dari lantai & 52 \\
\hline 3 & Lebar alas kursi & 39 \\
\hline 4 & Lebar sandaran & 35 \\
\hline 5 & Panjang sandaran & 31 \\
\hline 6 & Tinggi sandaran & 49 \\
\hline
\end{tabular}

(Sumber : Olah data)

\subsection{Spesifikasi Produk}

Produk ini terbuat dari bahan baku kayu yang kuat sebab penyangga beban hanya pada satu tiang dan empat kaki sehingga membutuhkan bahan baku dengan kayu yang kuat dan berbobot. Terdapat kuncian kursi yang digunakan saat menaikan atau menurunkan kursi sesuai dengan kenyamanan [13], [26], kekiri untuk proses mengunci dan kekanan untuk proses membuka. Sandaran digunakan untuk menyangga punggung agar lebih kuat serta beban dapat tertumpu dengan penopang kayu tersebut. Komponen-komponen dan hasil perancangan kursi kerja sebagai berikut : 


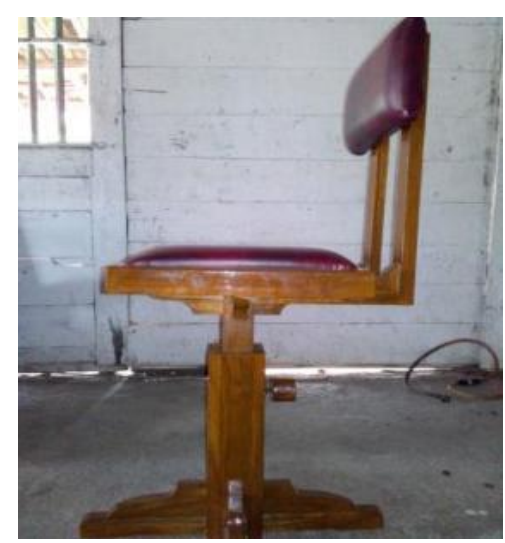

Gambar 2 Kursi Kerja yang Sudah Dikembangkan

Tabel 5 Spesifikasi Kursi

\begin{tabular}{|l|l|c|c|c|}
\hline \multirow{2}{*}{ No. } & \multicolumn{1}{|c|}{ Bahan } & \multicolumn{2}{c|}{ Ukuran $(\mathrm{cm})$} & \multirow{2}{*}{ Jumlah } \\
\cline { 3 - 4 } & & Panjang & Lebar & \\
\hline 1 & Kerangka Luar & & & \\
\hline & a. Kayu pipa kursi & 30 & 9 & 4 \\
\hline & b. Kaki kursi & 20,5 & 10 & 4 \\
\hline 2 & Kerangka Dalam & & & \\
\hline & a. Kayu pipa kursi dalam & 37 & 5 & 2 \\
\hline & b. Paku & - & - & 8 \\
\hline 3 & Tempat duduk kerangka & & & \\
\hline & a. Kayu & 35 & 5 & 4 \\
\hline & b. Tripleks & 31 & 31 & 1 \\
\hline & c. Busa & - & - & 1 \\
\hline & d. Kayu penyangga & 12 & 8 & 4 \\
\hline 4 & Sandaran Kerangka & & & \\
\hline & a. Kayu sandaran & 48 & 4 & 2 \\
\hline & b. Penyangga atas & 21 & 4 & 1 \\
\hline & c. Penyangga bawah & 24 & 2 & 2 \\
\hline
\end{tabular}

Tabel 6 Spesifikasi Kursi (lanjutan)

\begin{tabular}{|l|l|c|c|c|}
\hline \multirow{2}{*}{ No. } & \multicolumn{1}{|c|}{ Bahan } & \multicolumn{2}{c|}{ Ukuran $(\mathrm{cm})$} & \multirow{2}{*}{ Jumlah } \\
\cline { 3 - 4 } & & Panjang & Lebar & \\
\hline & d. Bantalan penyangga & 6 & 5 & 2 \\
\hline & e. Paku & - & - & 11 \\
\hline 5 & Pengunci kursi & & & \\
\hline & a. Baut & - & - & 1 \\
\hline & b. Paku & - & - & 1 \\
\hline & c. Penjepit & - & - & 3 \\
\hline & d. Pegangan & - & - & 1 \\
\hline \multicolumn{4}{|l|}{ Total } \\
\hline
\end{tabular}




\subsection{Interpretasi Hasil Studi Lapangan}

Interpretasi hasil studi lapangan yaitu penerapan hasil pengukuran ke dalam pembuatan desain serta produk. Dari hasil pengukuran menggunakan persentil ke-5 dan persentile ke-95 maka kursi kerja dapat dikembangkan dengan dinaikan atau diturunkan sesuai dengan ukuran persentil ke-5 dan ke-95 [27],[28].

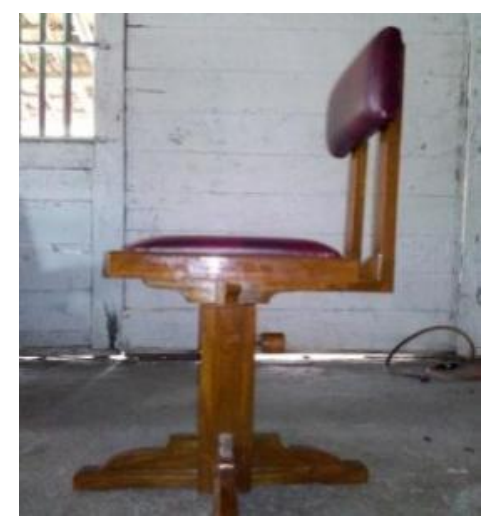

Gambar 3 Kursi kerja dengan persentil ke-5

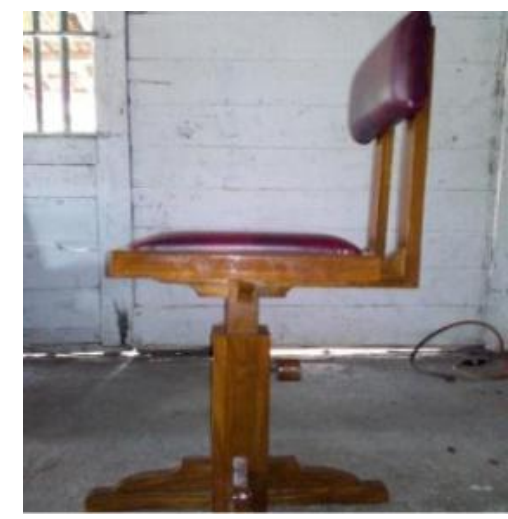

Gambar 4 Kursi kerja dengan persentil ke-95

\subsection{Uji Coba Produk Berdasarkan Kekuatan}

Uji coba produk dilakukan dengan system kenyamanan dan kekuatan serta efektif dan efisien produk. Uji coba produk ini dilakukan untuk mengetahui kekuatan serta kenyamanan alat setelah pengembangan [28], namun uji coba ini diakukan pada saat tidak melakukan proses produksi sebab dengan mengetahui tingkat kekuatan dan kenyamanan pun sudah dapat diketahui alat tersebut mempunyai tingkat kenyaman serta kekuatan dan efektif maupun efisien.

Tabel 7 Gambar uji coba kursi untuk mengetahui kekuatan

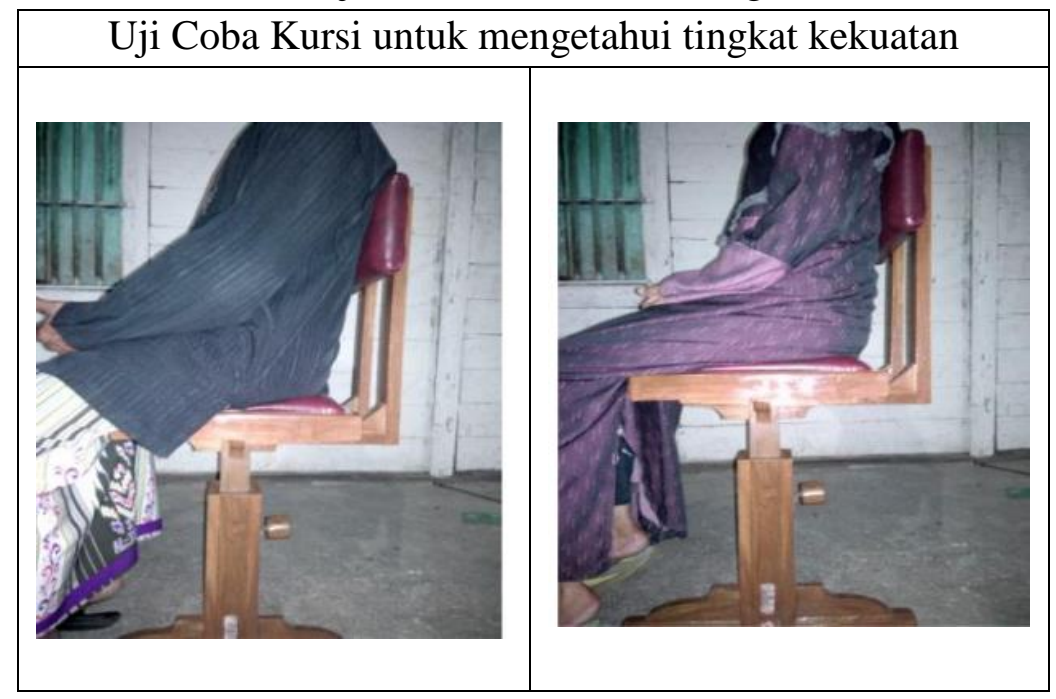

Dari hasil uji coba pada tabel diatas dapat diketahui tingkat kenyamanan yang terdapat pada sandaran kursi serta bantalan kursi, kemudian untuk tingkat kekuatan kursi dapat 
diketahui dari berat badan orang yang duduk di atas kursi dengan berat badan antara $40 \mathrm{~kg}$ sampai dengan $65 \mathrm{~kg}$.

\subsection{Uji Coba Produk Saat Digunakan}

Tabel 8 Uji Coba Kursi pada Saat Melakukan Aktivitas kerja

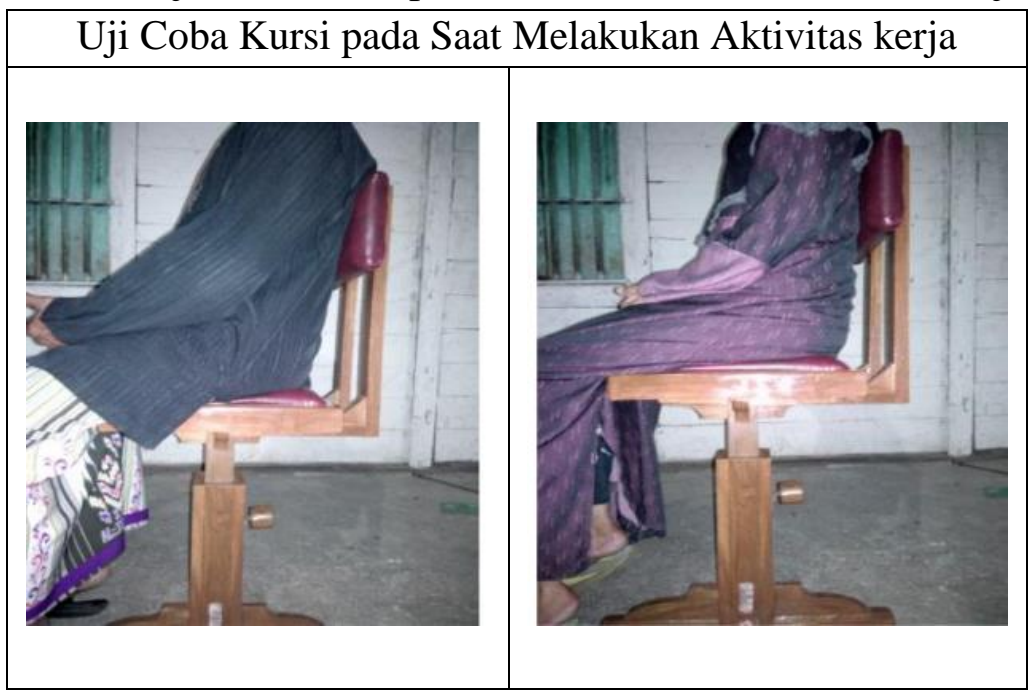

Dari hasil pengamatan terhadap uji coba kursi kerja terhadap pekerja setelah pengembangan maka dapat diketahui kondisi pekerja sebagai berikut :

1. Posisi duduk dengan memperhatikan posisi tulang belakang atau bahu.

2. Posisi duduk dengan memperhatikan siku terhadap meja tenun serta ketinggian kursi [29].

3. Sikap duduk dengan memperhatikan posisi badan saat melakukan aktivitas kerja tenun.

4. Posisi duduk dengan memperhatikan posisi kaki dan badan saat melakukan aktivitas tenun.

Namun pekerja masih sulit untuk menggunakan sandaran kerja saat melakukan aktivitas kerja sebab karena kebiasaan pekerja saat melakukan kegiatan kerja tanpa sandaran.

\subsection{Prinsip Keunggulan dan Kelemahan}

a. Prinsip-Prinsip

Prinsip yang digunakan untuk mengembangkan alat ini yaitu:

1. Ergonomi, dimana alat yang dikembangkan harus sesuai dengan pengukuran terhadap pekerja secara anthropometri sehingga dapat mengurangi keluhan sakit pada tulang bagian belakang.

2. Efisien, dimana alat yang dikembangkan dapat membantu dalam proses kegiatan kerja yang secara terus menerus selama 8 jam dengan memperhatikan kenyamanan dan keamanan proses kerja berlangsung.

3. Efektif, dimana alat yang dikembangkan dapat membantu kualitas kerja. 


\section{b. Keunggulan}

Keunggulan kursi kerja tenun yang sudah dikembangkan adalah:

a. Kursi dapat diatur tinggi rendahnya sesuai dengan pengukuran yang telah dilakukan.

b. Terdapat penambahan sandaran punggung serta bantalan pada alas duduk dan sandaran punggung yang memberi kenyamana terhadap pengguna.

\section{c. Kelemahan}

Adapun setiap produk pengembangan selain adanya kelebihan juga memiliki kelemahan, yaitu : menaikkan dan menurunkan kursi masih menggunakan bantuan dua tangan serta saat menaikkan dan menurunkan kursi pengguna untuk tidak duduk di tempat duduknya

\section{7. $\quad$ Faktor Pendukung dan Penghambat Implementasi}

Proses pengembangan produk ini menimbulkan faktor pendukung serta penghambat implementasi. Faktor pendukung pengembangan kursi kerja tenun ini adalah pekerja merasa kurang nyaman dengan tempat duduk serta sakit pada bagian tulang belakang saat bekerja secara terus-menerus. Pengembangan kursi kerja dengan sandaran punggung dapat sebagai alternative untuk mengurangi resiko kerja serta kursi yang dapat diatur naik turunya sesuai dengan pengukuran rata-rata pekerja. Faktor penghambat implementasi adalah kebiasaan terhadap posisi duduk kerja dengan aktivitas gerak tangan maka alat yang sudah disesuaikan dengan ukuran badan masih belum bisa untuk mengurangi resiko yang ditimbulkan akibat kerja.

\section{Kesimpulan}

Berdasarkan hasil analisis yang telah dilakukan maka dapat simpulan ergonomi pada kursi kerja tenun yang sudah dikembangkan dengan menambahkan sandaran serta pengatur ketinggian kursi kerja sesuai kondisi pekerja dengan mempertimbangkan: a) Posisi tulang belakang atau bahu, b) Posisi duduk dengan memperhatikan siku terhadap meja tenun serta ketinggian kursi, c) Sikap duduk dengan memperhatikan posisi badan saat melakukan aktivitas kerja tenun, d) Posisi duduk dengan memperhatikan posisi kaki dan badan saat melakukan aktivitas kerja. Dari hasil observasiyang dilakukan terhadap karyawan, kursi kerja sudah cukup nyaman dibandingkan dengan kursi kerja sebelumnya. Adanya penambahan bantalan pada alas tempat duduk serta pada alas sandaran dan pengaturan ketinggian kursi memberikan tingkat kenyaman dan mengurangi rasa sakit punggung. Dimensi-dimensi yang diamati secara anthropometri dengan menggunakan persentil ke-5 dan ke-95 yaitu: a) Tinggi siku duduk pekerja, b) Lebar bahu pekerja, c) Tinggi poplietal, d) Tinggi bahu duduk, e) Lebar pinggul. Dari pengukuran yang telah dilakukan terhadap dimensi-dimensi pekerja tersebut, kemudian dapat diketahui rata-rata setiap dimensi sehingga dapat menghasilkan rancangan pengembangan kursi kerja tenun. Berikut rancangan dimensi kursi kerja: 1) Tinggi kursi dari lantai $95 \mathrm{~cm}$, 2) Tinggi alas duduk dari lantai $52 \mathrm{~cm}, 3$ ) Lebar alas kursi $39 \mathrm{~cm}$, 4) Lebar sandaran $35 \mathrm{~cm}$, 5) Panjang sandaran 31 $\mathrm{cm}, 6)$ Tinggi sandaran $49 \mathrm{~cm}$. 


\section{Daftar Pustaka}

[1] D. Mayasari and F. Saftarina, "Ergonomi sebagai Upaya Pencegahan Musculoskeletal Disorders pada Pekerja,” JK Unila, 2016, doi: 10.1055/s-0034-1366979.

[2] A. Kristanto and D. A. Saputra, "Perancangan Meja dan Kursi Kerja yang Ergonomis pada Stasiun Kerja Pemotongan Sebagai Upaya Peningkatan Produktivitas," J. Ilm. Tek. Ind., 2011.

[3] Satriardi, D. A. Anggraini, and Y. Mitra, "PERANCANGAN KURSI KULIAH YANG ERGONOMIS DENGAN PENDEKATAN METODE QUALITY FUNCTION DEPLOYMENT (QFD),"S Semin. Nas. IENACO -, vol. 1, no. 1, pp. 2337-4349, 2017, doi: 10.1016/j.sbspro.2015.04.758.

[4] L. D. Indrasari and S. Rahayuningsih, "PERANCANGAN ALAT PENYARING TAHU SECARA ERGONOMIS,” Tek. Ind. Univ. Kadiri, pp. 1219-1229, 2017.

[5] S. Rahayuningsih and S. A. Sari, "Perancangan Kursi Dan Meja Lipat Untuk Mahasiswa ( Studi Kasus : Mahasiswa Universitas Kadiri ),” pp. 4-8, 2018.

[6] L. Tarwaka, Solichol, Sidiajeng, Ergonomi Untuk Keselamatan, Kesehatan Kerjadan Produktivitas. Surakarta: UNIBA PRES, 2004.

[7] Tarwaka, Ergonomi Industri, Dasar-dasar Pengetahuan dan Aplikasi di Tempat Kerja. Edisi Ke-2. 2015.

[8] K. K. E. H. K. A. D. K. Hoffman, Ergonomics 3rd Edition How to Design for Ease and Efficiency. Academic Press, 2018.

[9] A. S. N. J. E. Ridd, Health, Safety and Ergonomics 1st Edition, 1st ed. ButterworthHeinemann: Butterworth-Heinemann, 1988.

[10] H. dan Y. Iridiastadi, Ergonomi Suatu Pengantar, 4th ed. Bandung: PT. Remaja Rosdakarya, 2017.

[11] H. Iridiastadi and Yassierli, Ergonomi Suatu Pengantar, 1st ed. Bandung: Remaja Rosdakarya, 2015.

[12] F. A. Ekoanindiyo, “Analisa Perancangan Kursi Kuliah yang Ergonomi,” Din. Tek., vol. IV, No. 1, pp. 64-76, 2010.

[13] O. Tanudireja and M. Solahuddin, "Ergonomi Ditinjau dari Antropometri pada Interior Restoran Pizza-Hut di Surabaya Timur," J. INTRA, 2013.

[14] S. M. W. Wadya, "Ergonomi dalam Lingkungan Kerja," VEDC Malang, 2016. .

[15] N. Novziransyah, D. Syahputra, E. Depianti, and M. R. Mukhtar, "HUBUNGAN POSISI KERJA DENGAN KELUHAN MUSKULOSKELETAL PADA KARYAWANKARYAWATI SWALAYAN DIAMOND MEDAN JOHOR," J. Ris. Hesti Medan Akper Kesdam I/BB Medan, 2018, doi: 10.34008/jurhesti.v3i2.50.

[16] S. Wignjosoebroto, Ergonomi Studi Gerak dan Waktu, Edisi Pert. Jakarta: PT. Guna Widya, 1995.

[17] L. Dedy, “Antropometri," blogspot.com, 2012. .

[18] C. Zetterberg, M. Heiden, P. Lindberg, P. Nylén, and H. Hemphälä, "Reliability of a new risk assessment method for visual ergonomics," Int. J. Ind. Ergon., vol. 72, no. March, pp. 71-79, 2019, doi: 10.1016/j.ergon.2019.04.002.

[19] M. A. Jaworek, T. Marek, and W. Karwowski, "The scale of Work-Related Affective Feelings (WORAF)," Appl. Ergon., vol. 82, no. September 2018, p. 102945, 2020, doi: 10.1016/j.apergo.2019.102945.

[20] F. Wajdi and W. Kusmasari, "Resiko jenis pekerjaan terhadap keluhan Msds pada perawat RSUD Serang Banten," Tek. Ind. UMJ Jakarta, no. November 2015, pp. 1-7, 2015.

[21] A. Santoso, B. Anna, and A. Purbasari, "Perancangan Ulang Kursi Antropometri Untuk 
Memenuhi Standar Pengukuran," Profisiensi, 2014.

[22] A. S. Mariawati, A. Umyati, and F. Anggraini, "Identifikasi POstur Kerja Fisioterapis Stroke Excercise Rehabilitasi Medik Rumah Sakit Umum XYZ dengan Pendekatan RULA,” vol. ISSN: 2337, p. 8, 2016.

[23] I. Sulistiawan, H. B. Santoso, and A. Komari, "Perancangan Produk Kep Potong Rambut Dengan Mempertimbangkan Voice Of Customer Menggunakan Metode Quality Function Deployment," JATI UNIK J. Ilm. Tek. dan Manaj. Ind., vol. 2, no. 1, p. 43, 2019, doi: 10.30737/jatiunik.v2i1.386.

[24] I. Safi'i, "Penyusunan Konsep pada Perancangan \& Pengembangan Produk Penyusunan," 2019.

[25] M. Noviana and S. Hastanto, "Penerapan Metode Quality Function Deployment (Qfd) Untuk Pengembangan Desain Motif Batik Khas Kalimantan Timur," J@ Ti Undip J. Tek. Ind., vol. 9, no. 2, pp. 87-92, 2016, doi: 10.12777/jati.9.2.87-92.

[26] Laksmi Kusuma Wardani, "EVALUASI ERGONOMI DALAM PERANCANGAN DESAIN," Dimens. Inter., 2003.

[27] M. D. Angelica et al., "Determinants of Time Allocation across the Lifespan A Theoretical Model and an Application to the," PLoS One, 2012, doi: 10.1017/CBO9781107415324.004.

[28] J. A. Pradana and P. Popliteal, "REKAYASA KANSEI DALAM PENGEMBANGAN KONSEP PRODUK LACI Abstrak Program Studi Teknik Industri Fakultas Teknik , Universitas Pancasakti Tegal ISBN 978-623-7619-00-0 Program Studi Teknik Industri Fakultas Teknik , Universitas Pancasakti Tegal ISBN 978-623-7619-00-0,” vol. 2013, pp. 28-40, 2019.

[29] D. E. Gregory and S. E. Romero, "Can the use of an alternatively designed tamper alter spine posture and risk of upper limb injury while tamping espresso?," Int. J. Ind. Ergon., vol. 65, pp. 103-109, 2018, doi: 10.1016/j.ergon.2017.07.008. 